\title{
OPTIMIZATION OF THE STRUCTURES AT SHAKEDOWN AND ROSEN'S OPTIMALITY CRITERION
}

\author{
Piotr ALAWDIN ${ }^{1}$, Juozas ATKOČIŪNAS ${ }^{2}$, Liudas LIEPA ${ }^{2}$ \\ ${ }^{1}$ University of Zielona Gora, Zielona Góra, Poland \\ ${ }^{2}$ Vilnius Gediminas Technical University, Vilnius, Lithuania
}

\begin{abstract}
Paper focuses on the problems of application of extreme energy principles and nonlinear mathematical programing in the theory of structural shakedown. By means of energy principles, which describes the true stress-strain state conditions of the structure, the dual mathematical models of analysis problems are formed (static and kinematic formulations). It is shown how common mathematical model of the structures optimization at shakedown with safety and serviceability constraints (according to the ultimate limit state (ULS) and serviceability limit state (SLS) requirements) on the basis of previously mentioned mathematical models is formed. The possibilities of optimization problem solution in the context of physical interpretation of optimality criterion of Rosen's algorithm are analyzed.
\end{abstract}

Keywords: shakedown, extreme energy principles, optimal design, mathematical programing, Rosen's optimality criterion

\section{GENERAL NOTES}

The ideally elastic-plastic system is considered, which configuration and positions of external loads are known. Variable repeated loading (VRL) - the system of loads, where each of these loads or groups of these loads may vary

\footnotetext{
${ }^{1}$ Corresponding author: University of Zielona Gora, Institute of Civil Engineering, Szafrana st 1, 65-516 Zielona Góra, Poland, e-mail: p.aliawdin@ib.uz.zgora.pl, tel.+48683282322

${ }^{2}$ Corresponding author: Vilnius Gediminas Technical University, Department of Structural Mechanics, Sauletekio ave 11, 10223 Vilnius, Lithuania, e-mail: liudas.liepa@vgtu.lt, tel. +37052745216
} 
independently from each other. Structure, which is adapted to the VRL, is satisfying the strength conditions and does not experience a cyclic plastic collapse $[5,16,18]$. Although despite that the structures is at shakedown, there may appear such deformations and displacements, which can violate the exploitation conditions (serviceability limit state (SLS) requirements) $[14,17,19,22,30]$. Therefore in structural engineering it is important to know not only the true internal forces of the structure, which experienced plastic deformations, but did not reached the cyclic plastic collapse, but also the true deformations and displacements (the analysis problems of the structures) $[1,2,4,7]$. Many works on the theme of analysis and optimization of the structures deals with equations and dependencies for total (summarized) internal forces and displacements. This is not correct formulation of the problem, because the state of the structure before collapse is described by energy principles, therefore in the equations and dependencies of the problem there are namely residual internal forces and residual displacements $[25,28,36]$. On the other hand in today's scientific literature one can found, that the formulation of the residual stresses and displacements analysis problems are directly based on the classical shakedown theorems of Melan and Koiter [9,15,27]. In such case the application of mathematical programing is very narrowly adapted - as a tool for the solution of extremum problems only. Therefore the formulation of the rational solution algorithms for the nonlinear analysis problems of the stresses, deformations and displacements of the structures at shakedown, remains important in the theory of shakedown of plastic structures [21,24,32].

\section{DUALITY IN SHAKEDOWN ANALYSIS PROBLEMS}

Mathematical model for calculation problem of residual internal forces $\boldsymbol{S}_{r}=\boldsymbol{x}$ of elastic-plastic system, which is loaded with variable repeated load, according to the terms of mathematical programing theory can be written as follows:

find

$$
\begin{aligned}
\min & \tilde{f}(\boldsymbol{x}), \\
h_{i}(\boldsymbol{x})=0, & i=1,2, \ldots, m, \\
g_{i}(\boldsymbol{x}) \geq 0, & i=1,2, \ldots, \zeta .
\end{aligned}
$$

The mathematical model of analysis problem for statically admissible residual internal forces $S_{r}$ of the structures at shakedown (1)-(3) is formed according to the principle of supplementary deformation energy [18]. Function $\tilde{f}(\boldsymbol{x})$ expresses supplementary deformation energy, equations (2) - equilibrium equation, and constraints (3) are the yielding conditions. By eliminating the 
equations (2) from the analysis problem (1)-(3), the following problem is obtained:

find

$$
\begin{aligned}
\min & f(\boldsymbol{x}), \\
\varphi_{i}(\boldsymbol{x}) \geq 0, & i=1,2, \ldots, \zeta .
\end{aligned}
$$

subject to

(2) here can be performed using Jordan's rearrangements (from here on the variables are denoted as $\boldsymbol{x}$ ); another approach was proposed in [5].

From the theory of mathematical programing it is known, that for each extreme problem it is possible to form a dual problem [11]. This proves widely known proposition of mechanic's, where every extreme principle for solid body, which is formulated by the variables of forces, meets the dual principle, which is expressed in the terms of deformations state [18]. Mathematical model of dual problem for the problem (4)-(5) can be written as follows:

find

$$
\max \left\{f(\boldsymbol{x})-\sum_{i} \lambda_{i} \varphi_{i}(\boldsymbol{x})\right\},
$$

subject to

$$
\begin{gathered}
\frac{\partial f(\boldsymbol{x})}{\partial \boldsymbol{x}}+\sum_{i} \lambda_{i} \frac{\partial \varphi_{i}(\boldsymbol{x})}{\partial \boldsymbol{x}}=\mathbf{0}, \\
\lambda_{i} \geq 0, \quad i=1,2, \ldots, \zeta .
\end{gathered}
$$

Complementary slackness conditions of mathematical programming

$$
\lambda_{i} \varphi_{i}(x)=0, \quad i=1,2, \ldots, \zeta
$$

are included in to the objective function (6). Variables $\lambda_{i}$ in holonomic (when unloading is ignored) analysis problems of elastic-plastic structures obtains the physical meaning of plastic multipliers.

By changing the sign of the objective function the following problem is obtained:

find

$$
\min \left\{-f(x)+\sum_{i} \lambda_{i} \varphi_{i}(x)\right\},
$$

when conditions (7) and (8) are satisfied. This problem expresses the principle of complete potential energy minimum for the kinematically admissible residual displacements $\boldsymbol{u}_{r}(\lambda)$ [29], (see $\$ 4 \&$ \&). Formulations of problems (4)-(5), (6)(8) are used in forming dual mathematical models for the analysis problems of residual internal forces and deformations (displacements) of structures at shakedown. 


\section{PHYSICAL INTERPRETATION OF ROSEN'S OPTIMALITY CRITERION}

Problem (4)-(5) for the elastic-plastic structures under variable repeated loads is written as convex nonlinear mathematical programming problem:

find

$$
\min \left\{f(x)=\frac{1}{2} x^{T}[D] x \quad \mid x \in L\right\},
$$

here $\boldsymbol{L}=\left\{\boldsymbol{x} \mid \boldsymbol{\varphi}_{i}(\boldsymbol{x}) \geq 0\right.$ for every $\left.i=1,2, \ldots, m\right\}$ admissible variation domain of variables $\boldsymbol{x}$. In some cases objective function or constraints may be linear. Vector $\boldsymbol{x}^{*}$, which satisfies constraints of problem (11) and minimizes an objective function is called an optimal solution. Because the function $\varphi_{i}(x) \geq 0$ is convex and matrix $[D]$ (usually it is an elasticity matrix of the structure) is positively defined, global minimum of objective function in the domain $\boldsymbol{L}$ of admissible solutions is obtained.

Rosen's projective gradients algorithm is one of the convex mathematical programming problems solution algorithms. In Rosen's method the gradient of objective function is projected on the edge of the admissible domain [33,34]. The vector of solution direction is described by a gradient projection. Vector $\boldsymbol{x}^{*}$ is optimal solution if satisfies optimality criterion of Rosen's algorithm:

$$
\begin{gathered}
\left\{[I]-\left[\nabla \varphi\left(\boldsymbol{x}^{*}\right)\right]^{T}\left(\left[\nabla \varphi\left(\boldsymbol{x}^{*}\right)\right]\left[\nabla \varphi\left(\boldsymbol{x}^{*}\right)\right]^{T}\right)^{-1}\left[\nabla \varphi\left(\boldsymbol{x}^{*}\right)\right]\right\} \nabla f\left(\boldsymbol{x}^{*}\right)=\mathbf{0}, \\
\left(\left[\nabla \varphi\left(\boldsymbol{x}^{*}\right)\right]\left[\nabla \varphi\left(\boldsymbol{x}^{*}\right)\right]^{T}\right)^{-1}\left[\nabla \varphi\left(\boldsymbol{x}^{*}\right)\right] \nabla f\left(\boldsymbol{x}^{*}\right) \geq \mathbf{0},
\end{gathered}
$$

here $\nabla f\left(x^{*}\right), \nabla \varphi\left(x^{*}\right)$ - gradient of objective function $f(\boldsymbol{x})$ of problem (11) and gradient of active constraints $\varphi_{i}(\boldsymbol{x})=0 \quad(i \leq 1,2, \ldots, m, \quad i \in I)$. According to the formula (12) the projection of gradient $\nabla f\left(x^{*}\right)$ on the edge of admissible domain $\boldsymbol{L}$ is determined.

For the physical interpretation of optimality criterion the Kuhn-Tucker conditions are used [11]. Kuhn-Tucker conditions are related to the optimal solution $\boldsymbol{x}^{*}$ of the initial problem (11). For the convex functions Kuhn-Tucker conditions are as adequacy criterion for the global solution of the initial problem. It states [11]: $\boldsymbol{x}^{*}$ is an optimal solution if exists such scalar multipliers $\lambda_{i} \quad(i=1,2, \ldots, m)$, which satisfies the following conditions: 


$$
\begin{gathered}
\nabla f\left(\boldsymbol{x}^{*}\right)-\left[\nabla \varphi\left(\boldsymbol{x}^{*}\right)\right]^{T} \boldsymbol{\lambda}=\mathbf{0}, \\
\boldsymbol{\lambda}^{T} \varphi\left(\boldsymbol{x}^{*}\right)=0, \\
\boldsymbol{\lambda \geq \mathbf { 0 }} .
\end{gathered}
$$

In formulae (14)-(16) matrix of all gradients is used, not only of active constraints $\varphi_{i}(\boldsymbol{x})=0 \quad(i \leq 1,2, \ldots, m, \quad i \in I)$, therefore zero values of vector $\lambda \geq \mathbf{0}$ are determined by using complementary slackness conditions (15),(16). It is known, that in Kuhn-Tucker conditions (14)-(16) values of vector $\lambda$ are Lagrange multipliers. By comparing dependencies (12) and (14) can be seen, that if optimal solution $\boldsymbol{x}^{*}$ exists, physical meaning of conditions (13) is the vector of Lagrange multipliers for the problem (11):

$$
\lambda=\left(\left[\nabla \varphi\left(x^{*}\right)\right]\left[\nabla \varphi\left(x^{*}\right)\right]^{T}\right)^{-1}\left[\nabla \varphi\left(x^{*}\right)\right] \nabla f\left(x^{*}\right),
$$

Therefore, by using vectors $\boldsymbol{x}^{*}$ and $\boldsymbol{\lambda}$, variables of dual problem are obtained:

$$
\begin{gathered}
\boldsymbol{y}_{1}=\nabla f\left(\boldsymbol{x}^{*}\right)=[D] \boldsymbol{x}^{*}, \\
\boldsymbol{y}_{2}=\left[\frac{\partial \varphi\left(\boldsymbol{x}^{*}\right)}{\partial \boldsymbol{x}^{*}}\right] \boldsymbol{\lambda}=\left[\nabla \varphi\left(\boldsymbol{x}^{*}\right)\right]^{T} \boldsymbol{\lambda}, \\
\boldsymbol{y}_{1}-\boldsymbol{y}_{2}=\mathbf{0}, \\
\boldsymbol{\lambda}^{T} \varphi\left(\boldsymbol{x}^{*}\right)=0, \\
\boldsymbol{\lambda} \geq \mathbf{0} .
\end{gathered}
$$

In theory of mathematical programming conditions (12), by using projective matrix

$$
[P]=[I]-\left[\nabla \varphi\left(\boldsymbol{x}^{*}\right)\right]^{T}\left(\left[\nabla \varphi\left(\boldsymbol{x}^{*}\right)\right]\left[\nabla \varphi\left(\boldsymbol{x}^{*}\right)\right]^{T}\right)^{-1}\left[\nabla \varphi\left(\boldsymbol{x}^{*}\right)\right],
$$

are written as follows:

$$
[P] \nabla f\left(\boldsymbol{x}^{*}\right)=\mathbf{0} .
$$

In work [10] is shown, that Kuhn-Tucker conditions (14)-(16) in calculations of elastic-plastic structures are residual deformations compatibility equations. Therefore, Rosen's optimality criterion (12)-(13) has such meaning. And for the 
internal forces calculation problem, which is formulated according to Castiglian's principle, the following state is valid: the distribution of true residual internal forces $\boldsymbol{S}_{r}$ complies with satisfied deformation compatibility equations. In the case of cyclic-plastic collapse the dependencies of associative flow law are included in to deformations compatibility equations [3,5].

\section{DISCRETIZATION OF THE STRUCTURE}

Discretization of the structure, which geometry, materials and cross-sectional parameters are known, in this work is performed using a equilibrium finite elements method $[12,20,23]$. By using this method equilibrium equations are written more accurately compared with other types of finite elements. Also more accurately are described statically admissible elastic $\boldsymbol{S}_{e}$ and residual $\boldsymbol{S}_{r}$ internal forces of the structure at shakedown. In this work total internal forces are denoted as $\boldsymbol{S}=\boldsymbol{S}_{e}+\boldsymbol{S}_{r}$ and displacements $\boldsymbol{u}=\boldsymbol{u}_{e}+\boldsymbol{u}_{r}$.

Let's say, that the degree of freedom (DOF) of the structure is $m$, then the vectors of global displacements $\boldsymbol{u}$ and loads $\boldsymbol{F}$ are $\boldsymbol{u}=\left(u_{1}, u_{2}, \ldots, u_{m}\right)^{T}$ and $\boldsymbol{F}=\left(F_{1}, F_{2}, \ldots, F_{m}\right)^{T}$ respectively. The vector of internal forces of the element $k \quad(k=1,2, \ldots, \eta, k \in K) \quad$ with a number of $\eta_{k}$ nodal nodes $\left(l=1,2, \ldots, \eta_{k}, \quad l \in L\right)$ is $\boldsymbol{S}_{k}=\left(\boldsymbol{S}_{k 1}, \boldsymbol{S}_{k 2}, \ldots, \boldsymbol{S}_{k l}, \ldots, \boldsymbol{S}_{\eta_{k}}\right)^{T}$. Total number of vector's $\boldsymbol{S}_{k}$ components is $\eta_{k}$. Internal forces $\boldsymbol{S}_{k}(\boldsymbol{x})$ at any point $\boldsymbol{x}$ of the finite element are expressed as nodal points internal forces $\boldsymbol{S}_{k}$. The approximation functions of equilibrium finite element internal forces $S_{k}(x)$ are as follows:

$$
S_{k}(x)=\left[N_{k}(x)\right] S_{k}
$$

$\left[\boldsymbol{N}_{k}(\boldsymbol{x})\right]$ - approximation matrix of the $k$-th element, $\boldsymbol{S}_{k}-\eta_{k}$-dimensional vector of internal forces at element nodes. Usually functions $\left[N_{k}(x)\right]$ are such, that structure's element's differential equilibrium equations

$$
[A] S(x)=q(x)
$$

are not identically satisfied. Therefore equilibrium of the discrete model are ensured for the elements of the structure and for their main nodes [23]. By putting expression (26) into equations (27) and performing differentiation (if the 
load is evenly distributed, $\left.\boldsymbol{q}_{k}(\boldsymbol{x})=\boldsymbol{q}_{k}\right)$, the algebraic equilibrium equations of the finite element are obtained:

$$
\left[A_{k}(\boldsymbol{x})\right] \boldsymbol{S}_{k}=\boldsymbol{q}_{k}, \quad k \in K
$$

Here $\left[A_{k}(\boldsymbol{x})\right]=[A]\left[\boldsymbol{N}_{k}(\boldsymbol{x})\right]$. Separate elements are connected to the system by means of equilibrium equations for the main nodes of the elements [23]. Considering boundary conditions, the system of $m$ equilibrium equations of the structure is finally written as follows:

$$
[A] \boldsymbol{S}=\boldsymbol{F} \quad \text { or } \quad \sum_{k}\left[A_{k}\right] \boldsymbol{S}_{k}=\boldsymbol{F},
$$

[A] - equilibrium equation matrix of $(m \times n)$ order, which is used to find the vector of statically admissible residual internal forces $\boldsymbol{S}_{r}$. Residual internal forces $S_{r}$ are self-equilibrium, i.e. satisfies equilibrium equations:

$$
[A] \boldsymbol{S}_{r}=\mathbf{0} .
$$

The geometrical equations of the structure's discrete model are obtained by using principle of virtual works. For the individual $k$-th finite element these equations are as follows:

$$
\left[A_{k}\right]^{T} \boldsymbol{u}-\left[D_{k}\right] \boldsymbol{S}_{k}=\mathbf{0}, \quad k \in K .
$$

The elasticity matrix $\left[D_{k}\right]$ of the $k$-th element, in the local coordinates system, are calculated by the following formula:

$$
\left[D_{k}\right]=\int_{A_{k}}\left[\boldsymbol{N}_{k}(\boldsymbol{x})\right]^{T}[D]\left[\boldsymbol{N}_{k}(\boldsymbol{x})\right] d A .
$$

Integrating on the surface area $A_{k}$ of $k$-th element and taking into account boundary conditions, we have the geometrical equations for the whole discrete model of the structure:

$$
[A]^{T} \boldsymbol{u}-[D] \boldsymbol{S}=\mathbf{0},
$$

$[D]$ - quasidiagonal elasticity matrix of structure's elements. Physical meaning of vector's $\boldsymbol{u}$ components is determined by the formation order of the equilibrium equations (29) and dual interrelations between equilibrium 
$[A] \boldsymbol{S}=\boldsymbol{F}$ and geometrical $[A]^{T} \boldsymbol{u}-[D] \boldsymbol{S}=\mathbf{0}$ equations. By applying known finite elements procedures elastic displacements and elastic internal forces $S_{e}$ are easily obtained.

Variable repeated load $\boldsymbol{F}(t)$ is defined by timeless bounds $\boldsymbol{F}_{\text {sup }}$ and $\boldsymbol{F}_{\text {inf }}$ $\left(\boldsymbol{F}_{i n f} \leq \boldsymbol{F}(t) \leq \boldsymbol{F}_{\text {sup }}\right)$. For example, variation locus of two forces $F_{1}$ and $F_{2}$ can be illustrated as a tetragon, which apexes are combinations of forces bounds vectors components $\quad \boldsymbol{F}_{\text {inf }}=\left(\begin{array}{lll}F_{1, \text { inf }}, & F_{2, \text { inf }}\end{array}\right)^{T}, \quad \boldsymbol{F}_{\text {sup }}=\left(\begin{array}{ll}F_{1, \text { sup }}, & F_{2, \text { sup }}\end{array}\right)^{T}$. The set of apexes is $j \in J \quad\left(j=1,2, \ldots, p, \quad p=2^{m}\right)$; i.e., if $m=2$ then $p=4$. By solving residual internal forces and displacements analysis problem of the structure at shakedown, vectors $\boldsymbol{F}_{\text {sup }}$ and $\boldsymbol{F}_{\text {inf }}$ are known, therefor tetragon is fixed from changing form.

Vectors of elastic solution $S_{e j}$ are linear functions of load variation bounds $\boldsymbol{F}_{s u p}$, $\boldsymbol{F}_{i n f}$ and defines all apexes of elastic internal forces hodograph $j \in J$ :

$$
\boldsymbol{S}_{e}(t)=[\alpha] \boldsymbol{F}(t)
$$

Here $[\alpha]$ - an influence matrix of elastic internal forces.

Nonlinear yielding condition of the elastic-plastic element cross-section

$$
\varphi=C-f\left(S_{e}(t)+S_{r}(t)\right) \geq 0
$$

is suitable for the case when the shakedown process of the structure is investigated during time $t$ (considering every possible loading history $\boldsymbol{F}(t)$ ). The plasticity constant $C=\left(S_{0}\right)^{2}$ is related to the dimensions and material of the cross-section, e.g. limit internal force $S_{0}$. These limit internal forces $S_{0 k} \quad(k \in K)$ are considered constant within bounds of $k$-th finite element. For the shakedown state of the structure residual internal forces $S_{r}$ in each section of the structure must correspond to the yielding conditions (35) for each apex $j$ of elastic internal forces $\boldsymbol{S}_{e}(t)=[\alpha] \boldsymbol{F}(t)$ hodograph:

$$
\varphi_{j}=C_{k}-f_{j}\left(S_{e j}+S_{r}\right) \geq 0, \quad j \in J .
$$

Thus yielding conditions are checked at each nodal point $l$ of the $k$-th finite element: 


$$
\varphi_{k l, j}=C_{k}-f_{k l, j}\left(S_{e k l, j}+S_{r k l}\right) \geq 0, \quad k \in K, \quad l \in L, \quad j \in J .
$$

Yielding conditions of the whole elastic-plastic structure are written as follows:

$$
\boldsymbol{\varphi}_{j}=\boldsymbol{C}-\boldsymbol{f}_{j}\left(\boldsymbol{S}_{e j}+\boldsymbol{S}_{r}\right) \geq 0, \quad j \in J .
$$

Here $\boldsymbol{C}=\left(C_{1}, C_{2}, \ldots, C_{k}, \ldots, C_{\eta}\right)^{T}$ - vector of plasticity constants of whole structure.

Statically admissible residual internal forces $S_{r}$ satisfies equilibrium equations (30) and yielding conditions (38).

Kinematically admissible residual displacements $\boldsymbol{u}_{r}$ of the elastic-plastic structure satisfies geometrical equations (33):

$$
[A]^{T} \boldsymbol{u}_{r}=[D] \boldsymbol{S}_{r}+\boldsymbol{\Theta}_{p},
$$

$\boldsymbol{\Theta}_{p}=\left(\boldsymbol{\Theta}_{p k l}\right)^{T}-$ vector of plastic deformations. Components of vector $\boldsymbol{\Theta}_{p}$ are calculated according to formula:

$$
\begin{gathered}
\boldsymbol{\Theta}_{p k l}=\sum_{j} \boldsymbol{\Theta}_{p k l, j}=\sum_{j}\left[\nabla \varphi_{k l, j}\left(S_{e k l, j}+\boldsymbol{S}_{r k l}\right)\right]^{T} \lambda_{k l, j}, \quad \lambda_{k l, j} \boldsymbol{\varphi}_{k l, j}=0, \\
\lambda_{k l, j} \geq 0, \quad k \in K, \quad l \in L, \quad j \in J .
\end{gathered}
$$

Here $\left[\nabla \varphi_{k l, j}\left(\boldsymbol{S}_{e k l, j}+\boldsymbol{S}_{r k l}\right)\right]^{T}=\left[\frac{\partial f_{k l, j}\left(\boldsymbol{S}_{e k l, j}+\boldsymbol{S}_{r k l}\right)}{\partial \boldsymbol{S}_{r k l}}\right]$ - gradients of yielding conditions (36), $\lambda_{k l, j}$ - plastic multipliers. Residual internal forces $\boldsymbol{S}_{r}$ caused by the plastic deformations $\boldsymbol{\Theta}_{p}$ in the structure at shakedown ensures, that during load variation new plastic deformations will not appear. Residual deformations $\boldsymbol{\Theta}_{r}=[D] \boldsymbol{S}_{r}+\boldsymbol{\Theta}_{p}$ and residual displacements $\boldsymbol{u}_{r}$ of the structure at shakedown may not be unique: they depends on the particular history of loading $\boldsymbol{F}(t)$.

\section{COMMON MODEL OF OPTIMIZATION OF THE STRUCTURE AT SHAKEDOWN}

The paper refers the optimal shakedown design problem of the structure at shakedown as follows: for given load variation bounds $\boldsymbol{F}_{\text {inf }}, \boldsymbol{F}_{\text {sup }}$, the vector of 
limit forces $S_{0}$ satisfying optimality criterion $\min \sum_{k} L_{k} S_{0 k}$, and the constraints of shakedown and stiffness, should be found:

find

$$
\min \sum_{k} L_{k} S_{0 k}
$$

subject to

$$
[A] \boldsymbol{S}_{r}=\mathbf{0},
$$

$$
\begin{gathered}
\boldsymbol{\varphi}_{j}=\boldsymbol{C}\left(\boldsymbol{S}_{0}\right)-\boldsymbol{f}_{j}\left(\boldsymbol{S}_{e, j}\left(\boldsymbol{S}_{0}\right)+\boldsymbol{S}_{r}\right) \geq \mathbf{0}, \\
{\left[D\left(\boldsymbol{S}_{0}\right)\right] \boldsymbol{S}_{r}+\boldsymbol{\Theta}_{p}\left(\boldsymbol{S}_{0}\right)-[A]^{T} \boldsymbol{u}_{r}=\mathbf{0},}
\end{gathered}
$$

$$
\boldsymbol{\Theta}_{p}\left(\boldsymbol{S}_{0}\right)=\sum_{j}\left[\nabla \boldsymbol{f}_{j}\left(\boldsymbol{S}_{e, j}\left(\boldsymbol{S}_{0}\right)+\boldsymbol{S}_{r}\right)\right]^{T} \boldsymbol{\lambda}_{j}
$$$$
\lambda_{j}^{T}\left[C\left(S_{0}\right)-f_{j}\left(S_{e, j}\left(S_{0}\right)+S_{r}\right)\right]=0,
$$$$
\lambda_{j} \geq \mathbf{0}, \quad \lambda_{j}=\left[\begin{array}{llll}
\lambda_{1, j} & \lambda_{2, j} & \ldots & \lambda_{\zeta, j}
\end{array}\right]^{T},
$$$$
\boldsymbol{S}_{0} \geq \boldsymbol{S}_{0, \min }
$$

$$
\boldsymbol{u}_{\min } \leq \boldsymbol{u}_{e, j}\left(\boldsymbol{S}_{0}\right)+\boldsymbol{u}_{r} \leq \boldsymbol{u}_{\max },
$$

$$
\boldsymbol{S}_{e, j}=\left[\alpha\left(\boldsymbol{S}_{0}\right)\right] \boldsymbol{F}_{j}, \quad \boldsymbol{u}_{e, j}=\left[\beta\left(\boldsymbol{S}_{0}\right)\right] \boldsymbol{F}_{j} \quad \text { for all } j \in J,
$$

where $\boldsymbol{S}_{0}, \quad \boldsymbol{S}_{r}, \quad \boldsymbol{u}_{r}, \lambda_{j}$ are unknowns. Objective function (41) can express the distribution of limit internal forces $S_{0}$ or directly the volume of the structure $[3,8,31]$. The admissible bounds of displacements, under stiffness conditions (49) $\boldsymbol{u}_{\min }$ and $\boldsymbol{u}_{\max }$, can be determined according to design standards [13]. Mathematical model (41)-(50) is a continuous optimization problem. The multiextremity of problem (41)-(50) is determined by complementary slackness conditions for mathematical programing (46). Problem (41)-(50) has to be solved in an iterative manner [3,8,31]. A vector of limit forces of the first iteration $S_{0}^{*(1)}$ is obtained in the first solution of the problem with the initial data (initial elemental flexibility matrix $[D]$ ). A new flexibility matrix is formed using new forces $S_{0}^{*(1)}$. Then, new influence matrices $[\alpha],[\beta]$ can be calculated along with new elastic forces $\boldsymbol{S}_{e, j}=[\alpha] \boldsymbol{F}_{j}$ and displacements $\boldsymbol{u}_{e, j}=[\beta] \boldsymbol{F}_{j}$. Iterations are continued until the difference between two consecutive objective function values is as small as desired. 


\section{NUMERICAL EXAMPLE OF 2D FRAME VOLUME OPTIMIZATION AT SHAKEDOWN CONDITIONS}

The known geometry four-storey plane (two dimensional) frame structure is considered (Fig. 2). Columns of the frame are designed from standard rolled HEB type cross-sections, beams of the frame are designed from standard rolled IPE type cross sections. Bending stiffness $E I$ and axial stiffness $E A$ of elements are known (where $E=205000$ - elastic modulus of steel, N/mm $; I=I_{y}=a_{1} A^{b_{1}}$ - second moment of cross-sectional area, $\mathrm{cm}^{4} ; A$ - cross-sectional area, $\mathrm{cm}^{2}$ (Table 1); $a_{1}$ and $b_{1}$ are known relation constants, provided in Table $2[6,35]$ ). Limit bending moment $M_{0}=f_{y} W_{p l}$ and limiting axial force $N_{0}=f_{y} A$ of frame members are known (where $f_{y}=253.2$ - yield strength of steel, $\mathrm{N} / \mathrm{mm}^{2}$, $W_{p l}=W_{p l, y}=a_{3} A^{b_{3}}$ - plastic section modulus, $\mathrm{m}^{3} ; a_{3}$ and $b_{3}$ are known relation constants, provided in Table $2[6,35])$, see Fig. 1a. The frame is subjected to variable repeated loading, i.e. two concentrated forces $F_{1}(t)$ and $F_{2}(t)$, varying in time, are applied and their variation bounds are $0 \leq F_{1}(t) \leq 200.0 \mathrm{kN}$ and $-33.3 \leq F_{2}(t) \leq 160.6 \mathrm{kN}$. Optimization problem (41)-(50) (excluding conditions (49)) is solved (using MATLAB solver: fmincon): it is determined if the frame under given loading experiences shakedown, the residual internal forces $\boldsymbol{S}_{r}^{*}$, which ensures shakedown process, plastic deformations $\boldsymbol{\theta}_{p}^{*}$ and residual displacements $\boldsymbol{u}_{r}^{*}$ are obtained, as well limit internal forces $\boldsymbol{S}_{0}$.

Table 1. Cross-sectional properties of initial cross-sections

\begin{tabular}{cccc} 
& $A, \mathrm{~cm}^{2}$ & $I_{y}=a_{1} A^{b_{1}}, \mathrm{~cm}^{4}$ & $W_{p l, y}=a_{3} A^{b_{3}}, \mathrm{~cm}^{3}$ \\
\hline HEB 550 & 254.1 & 143011.45 & 5632.43
\end{tabular}

Table 2. Cross-sectional properties relation constants

\begin{tabular}{ccccc}
\hline \multirow{2}{*}{ Name of I-shape } & \multicolumn{2}{c}{$I_{y}$} & \multicolumn{2}{c}{$W_{p l, y}$} \\
\cline { 2 - 5 } & $a_{1}$ & $b_{1}$ & $a_{3}$ & $b_{3}$ \\
\hline HEB 550-1000 & 0.0010 & 3.3910 & 0.0402 & 2.1399 \\
\hline IPE & 0.7885 & 2.3210 & 0.8411 & 1.6572 \\
\hline
\end{tabular}


In case of standard steel rolled I-shape cross-sections the yielding conditions for the $i$-th cross-section read:

$$
\left.\begin{array}{l}
M_{e i}+M_{r i}-M_{o i} \leq 0, \\
M_{e i} / 1.18+c_{i}^{+} N_{e i}+M_{r i} / 1.18+c_{i}^{+} N_{r i}-M_{o i} \leq 0, \\
M_{e i} / 1.18-c_{i}^{-} N_{e i}+M_{r i} / 1.18-c_{i}^{-} N_{r i}-M_{o i} \leq 0, \\
-M_{e i}-M_{r i}-M_{o i} \leq 0, \\
-M_{e i} / 1.18+c_{i}^{+} N_{e i}-M_{r i} / 1.18+c_{i}^{+} N_{r i}-M_{o i} \leq 0, \\
-M_{e i} / 1.18-c_{i}^{-} N_{e i}-M_{r i} / 1.18-c_{i}^{-} N_{r i}-M_{o i} \leq 0
\end{array}\right\}
$$

Graphical interpretation of yielding conditions (51) is shown in Fig 1.

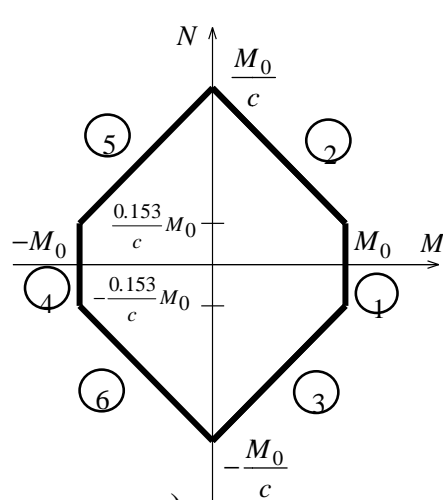

a)

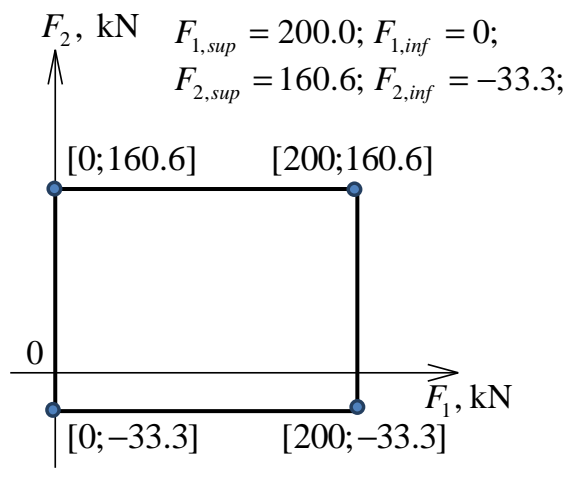

b)

Fig. 1 Graphical interpretation of linearized yielding conditions of I-shape cross-section (a); load variation locus (b)

In this work as the main limit internal force the limit bending moment $M_{0 i}$ is chosen. Therefore the relations between limit bending moment and limit axial force of the cross-sections are expressed as eccentricities $c^{+}$and $c^{-}[26,35]$. For the elements under tension they read:

$$
c^{+}=\frac{M_{0 i}}{N_{0 i}}=\frac{\sigma_{y} a_{3} A^{b_{3}}}{\sigma_{y} A}=a_{3} A^{b_{3}-1},
$$

for the elements under compression:

$$
c^{-}=\frac{M_{0 i}}{N_{c r, i}}=\frac{\sigma_{y} a_{3} A^{b_{3}}}{\chi \sigma_{y} A}=\frac{a_{3}}{\chi} A^{b_{3}-1} .
$$


Here $N_{c r}=\sigma_{c r} A=\chi \sigma_{y} A-$ limit/critical axial internal force (the design buckling resistance of a member under compression). $\chi$ - reduction coefficient which depends on the non-dimensional slenderness $\bar{\lambda}$ of a column [13,26,37]. In this paper the lower bound of constructional requirements $S_{0, \min }(48)$ is compatible with the minimum value of limit bending moment $M_{0, c r}^{\min }$. Due to requirements of limit slenderness $\lambda_{\text {lim }}=120$ [13,37], then the minimum value of limit bending moment read [26,31]:

$$
M_{0, c r}^{\min }=\sigma_{y} a_{3}\left(\frac{l_{b}^{2}}{a_{1} \lambda_{\text {lim }}^{2}}\right)^{\frac{b_{3}}{b_{1}-1}} .
$$

The buckling length $l_{b}$ for the columns were determined according to requirements as established by national Lithuanian structural requirements (STR) [37]. No structural requirements of minimum slenderness of beams have been considered.

Calculation scheme of the structure is shown in a Figure 2.

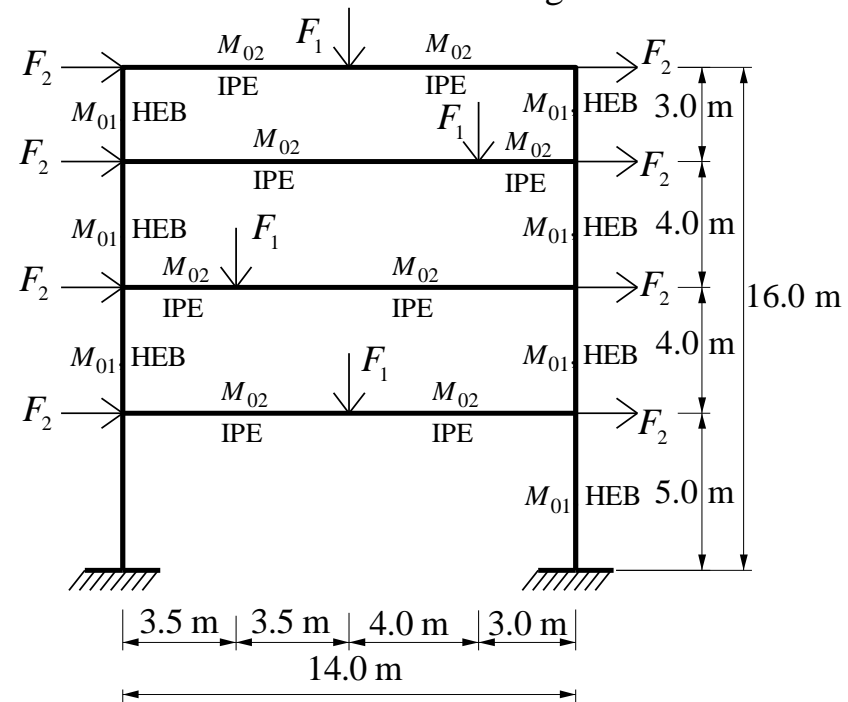

Fig 2. Calculation scheme of the frame

Discrete model of the structure consist of 16 finite elements, 14 nodes, each element has a section at each end, and therefore total number of computational sections is 32. Each element has a bending moment acting at each section and an axial internal force (one per element), therefore total number of internal forces are 48. Degree of freedom (DOF) is 36. 
Table 3. Possible loading combinations

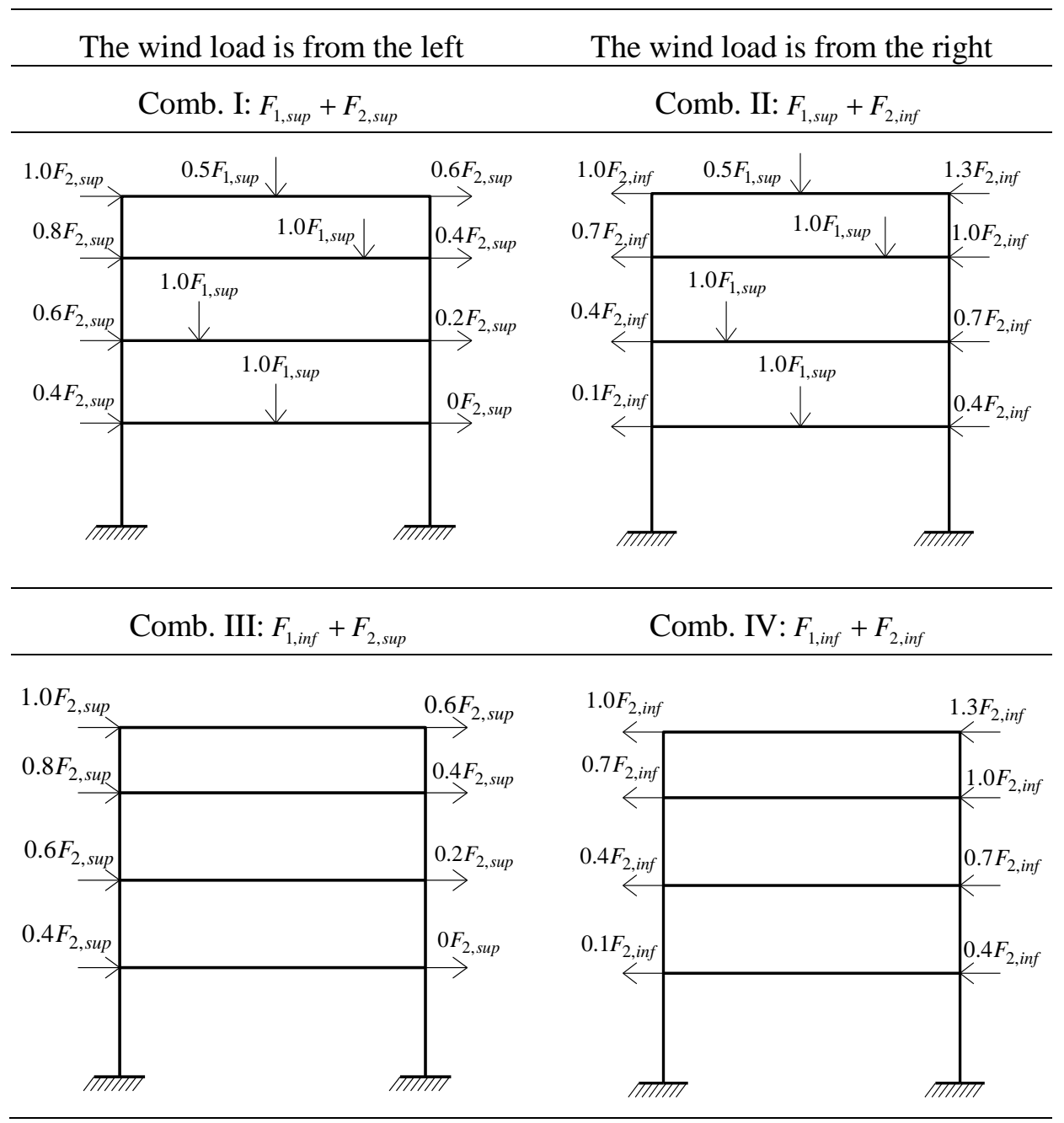

The optimum design was obtained after 30 iterations (see Table 4, Fig. 3). The optimal cross-section areas of frame members were chosen according to the limit moments distribution (see Table 4). The minimal volume of such structure under given loads, at shakedown is $V_{o p t}=1.5161 \mathrm{~m}^{3}$.

Maximal horizontal linear total displacement located at the top beam is

$$
u_{\max }^{\text {hor }}=u_{e, \max }^{\text {hor }}+u_{r}^{\text {hor }}=0.1056+0.0444=0.15 \mathrm{~m} .
$$


Table 4. The optimum volume of 4-storey steel frame solution convergence per iterations

\begin{tabular}{cccccc}
\hline $\begin{array}{c}\text { Iter. } \\
\text { No. }\end{array}$ & Volume, $\mathrm{m}^{3}$ & $M_{01}, \mathrm{kNm}$ & $M_{02}, \mathrm{kNm}$ & $A_{1}, \mathrm{~cm}^{2}$ & $A_{2}, \mathrm{~cm}^{2}$ \\
\hline 0 & 0.8708 & 64105.0608 & 9.4273 & 254.1 & 10.3 \\
\hline 1 & 1.9385 & 3815.2648 & 463.3528 & 416.7315 & 108.0309 \\
\hline 2 & 1.5864 & 1076.4244 & 811.1802 & 230.7010 & 151.4625 \\
\hline 3 & 1.3227 & 1006.4545 & 466.2454 & 223.5676 & 108.4374 \\
\hline$\ldots$ & $\ldots$ & $\ldots$ & $\ldots$ & $\ldots$ & $\ldots$ \\
\hline 28 & 1.5032 & 1363.6641 & 560.5426 & 257.6638 & 121.1852 \\
\hline 29 & 1.5107 & 1401.2863 & 556.4239 & 260.9617 & 120.6471 \\
\hline 30 & 1.5161 & 1404.6600 & 562.5669 & 261.2552 & 121.4491 \\
\hline \multicolumn{7}{c}{ Optimal cross-sections } \\
\end{tabular}

Convergence of structure's volume $\left(\mathrm{m}^{3}\right)$ per iteration is shown in graph bellow (see Fig. 3).

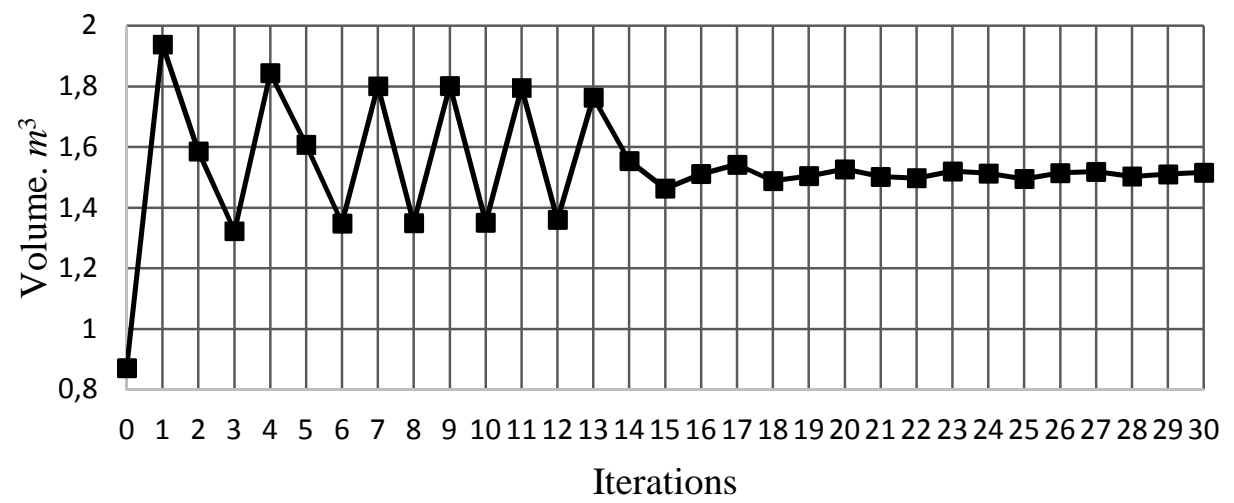

Fig. 3. Convergence of structure's volume $\left(\mathrm{m}^{3}\right)$ per iterations

\section{CONCLUSIONS}

1. Static (lower bound) shakedown theorem enables to create an optimization problems using equilibrium finite elements.

2. The admissible stress-strain state of a structure at shakedown is described by Euler-Lagrange equations for the plastic state.

3. Optimization problem of the structure at shakedown conditions is a nonconvex mathematical programming problem. 
4. Numerical example showed, that mathematical model of optimization problem could be updated with a constraints of local and global stability of structures elements (e.g. constraints for limit slenderness according to EC3 serviceability limit state (SLS) requirements).

\section{REFERENCES}

1. Alawdin P, Bulanov G.: Shakedown of Composite Frames Taking into Account Plastic and Brittle Fracture of Elements. Civ Environ Eng Reports. 2015;15(4). doi:10.1515/ceer-2014-0031.

2. Alawdin P, Kasabutski S.: Limit and shakedown analysis of RC rod cross $\square$ sections. J Civ Eng Manag. 2009;15(1):59-66. doi:10.3846/13923730.2009.15.59-66.

3. Alawdin P, Liepa L.: Optimal shakedown analysis of plane reinforced concrete frames according to Eurocodes. Int J Mech Mater Des. December 2015. doi:10.1007/s10999-015-9331-0.

4. Alawdin P, Muzychkin Y.: Limit analysis of structures with destructible elements under impact loadings. Eng Trans. 2011;59(3):139-159.

5. Alawdin P.: Limit Analysis of Structures under Variable Loads. Minsk: Tekhnoprint; 2005. http://isbnplus.org/9789854647272.

6. Atkočiūnas J, Karkauskas R.: Optmization of Elastic Plastic Beam Structures. Vilnius, Lithuania: Vilnius Gediminas Technical University; 2010. doi:10.3846/1137-S.

7. Atkočiūnas J, Norkus A.: Method of fictitious system for evaluation of frame shakedown displacements. Comput Struct. 1994;50(4):563-567. doi:10.1016/0045-7949(94)90027-2.

8. Atkočiūnas J, Ulitinas $\mathrm{T}$, Kalanta $\mathrm{S}$, Blaževičius G.: An extended shakedown theory on an elastic-plastic spherical shell. Eng Struct. 2015;101:352-363. doi:10.1016/j.engstruct.2015.07.021.

9. Atkočiūnas J. Mathematical models of optimization problems at shakedown. Mech Res Commun. 1999;26(3):319-326. doi:10.1016/S00936413(99)00030-0.

10. Atkočiūnas J.: Optimal Shakedown Design of Elastic-Plastic Structures. Vilnius, Lithuania: Vilnius Gediminas Technical University; 2012. doi:10.3846/1240-S.

11. Bazaraa MS, Sherali HD, Shetty CM. Nonlinear Programming: Theory and Algorithms. Hoboken, NJ, USA: John Wiley \& Sons, Inc.; 2006. doi:10.1002/0471787779.

12. Belytschko T, Liu WK, Moran B, Elkhodary K.: Nonlinear Finite Elements for Continua and Structures. II edition.; 2013. http://eu.wiley.com/WileyCDA/WileyTitle/productCd-1118632702.html. 
13. BS EN 1993-1-1. Eurocode 3: Design of steel structures. Part 1-1: General rules and rules for buildings. 2005.

14. Capurso M, Corradi L, Maier G.: Bounds on deformations and displacements in shakedown theory. In: Materiaux et Structures Sous Chargement Cyclique, Ass. Amicale Des Ingenieurs Anciencs Eleves de l'E.N.P.C. Paris; 1979:231-244.

15. Casciaro R, Garcea G.:An iterative method for shakedown analysis. Comput Methods Appl Mech Eng. 2002;191(49-50):5761-5792. doi:10.1016/S00457825(02)00496-6.

16. Cohn MZ, Maier G.: Engineering Plasticity by Mathematical Programming. Pergamon Press; 1979.

17. Čyras A, Atkočiūnas J.: Mathematical model for the analysis of elasticplastic structures under repeated-variable loading. Mech Res Commun. 1984;11(5):353-360. doi:10.1016/0093-6413(84)90082-X.

18. Čyras A.: Extremum principles and optimization problems for linearly strain hardening elastoplastic structures. Appl Mech. 1986;22(4):89-96.

19. Daniūnas A, Kvedaras AK, Šapalas A, Šaučiuvènas G.: Design basis of Lithuanian steel and aluminium structure codes and their relations to Eurocode. J Constr Steel Res. 2006;62(12):1250-1256. doi:10.1016/j.jcsr.2006.04.018.

20. Gallagher RH. Finite Element Analysis: Fundamentals. Englewood Cliffs: Prentice-Hall; 1975. http://doi.wiley.com/10.1002/nme.1620090322.

21. Giambanco F, Palizzolo L, Caffarelli A.: Computational procedures for plastic shakedown design of structures. Struct Multidiscip Optim. 2004;28(5):317-329. doi:10.1007/s00158-004-0402-3.

22. Kala Z.: Sensitivity analysis of the stability problems of thin-walled structures. J Constr Steel Res. 2005;61(3):415-422. doi:10.1016/j.jcsr.2004.08.005.

23. Kalanta S.: The equilibrium finite elements in computation of elastic structures. Statyba. 1995;1(1):25-47. doi:10.1080/13921525.1995.10531500.

24. Kaliszky S, Lógó J.: Plastic behaviour and stability constraints in the shakedown analysis and optimal design of trusses. Struct Multidiscip Optim. 2002;24(2):118-124. doi:10.1007/s00158-002-0222-2.

25. Kaliszky S.: Elastoplastic Analysis with Limited Plastic Deformations and Displacements. Mech Struct Mach. 1996;24(1):39-50. doi:10.1080/08905459608905254.

26. Karkauskas R.: Optimisation of geometrically non-linear elastic-plastic structures in the state prior to plastic collapse. J Civ Eng Manag. 2007;13(3):37-41. doi:10.1080/13923730.2007.9636436.

27. Koiter WT.: General Theorems for Elastic-plastic Solids. In: Sneddon IN, Hill R, eds. Progress in Solid Mechanics. Amsterdam: North-Holland; 
1960:165-221. https://books.google.lt/books?id=EP33GgAACAAJ.

28. König JA, Kleiber M.: On a new method of shakedwon analysis. Bull l'academie Pol des Sci Ser des Sci Tech. 1978;26(4):167-171.

29. König JA.: Shakedown of Elastic-Plastic Structures. Vol 7. Amsterdam: Elsevier; 1987. doi:10.1016/B978-0-444-98979-6.50018-9.

30. Lange-Hansen P. Comparative Study of Upper Bound Methods for the Calculation of Residual Deformations After Shakedown. Department of Structural Engineering and Materials, Technical University of Denmark; 1998.

31. Liepa L, Karkauskas R.: Calculation of elastic-plastic geometrically nonlinear frames. Sci - Futur Lith. 2012;4(4):326-334. doi:10.3846/mla.2012.51.

32. Mróz Z, Weichert D, Dorosz S, eds.: Inelastic Behaviour of Structures under Variable Loads. Vol 36. Dordrecht: Springer Netherlands; 1995. doi:10.1007/978-94-011-0271-1.

33. Rosen JB.: The Gradient Projection Method for Nonlinear Programming. Part I. Linear Constraints. J Soc Ind Appl Math. 1960;8(1):181-217. doi:10.1137/0108011.

34. Rosen JB. The Gradient Projection Method for Nonlinear Programming. Part II. Nonlinear Constraints. J Soc Ind Appl Math. 1961;9(4):514-532. doi:10.1137/0109044.

35. Saka MP, Kameshki ES.: Optimum design of unbraced rigid frames. Comput Struct. 1998;69(4):433-442. doi:10.1016/S0045-7949(98)00117-5.

36. Stein E, Zhang G, Mahnken R.: Shakedown analysis for perfectly plastic and kinematic hardening materials. In: CISM. Progress in Computernal Analysis or Inelastic Structures. Vienna: Springer Vienna; 1993:175-244. doi:10.1007/978-3-7091-2626-4_4.

37. STR 2.05.08:2005. Design of Steel Structures. 2005.

\section{OPTYMALIZACJA KONSTRUKCJI W STANIE PRZYSTOSOWANIA A KRYTERIUM OPTYMALNOŚCI ROSENA}

\section{Streszczenie}

W pracy przedstawiono problemy zastosowania ekstremalnych zasad energetycznych i nieliniowego programowania matematycznego $\mathrm{w}$ teorii przystosowania konstrukcji. Za pomocą zasad energetycznych, które opisują rzeczywiste stany naprężenia-odkształcenia konstrukcji, tworzone są dualne modele matematyczne analizowanych problemów (sformułowania statyczne i kinematyczne). Pokazano jak na podstawie wyżej wymienionych modeli matematycznych formułowany jest ogólny model matematyczny 
optymalizacji konstrukcji przy uwzględnieniu ograniczeń w postaci stanów granicznych nośności/bezpieczeństwa i użytkowalności. Analizowane są możliwości rozwiązania problemu optymalizacji w kontekście fizycznej interpretacji kryterium optymalności algorytmu Rosena.

Słowa kluczowe: przystosowanie, ekstremalne zasady energetyczne, projektowanie optymalne, programowanie matematyczne, kryterium optymalności Rosena

Editor received the manuscript: 15.07.2016 
